\title{
HOW USABLE IS A SMARTPHONE WITH A MĀORI-LANGUAGE INTERFACE?
}

\author{
Paora Mato* \\ Te Taka Keegan \\ Leilani Naera ${ }^{\ddagger}$
}

\begin{abstract}
Major languages dominate contemporary technologies. For Māori, there is opportunity to engage with some technologies using their language and to participate within Māori-language communities in various digital media. A smartphone launched by Two Degrees Mobile Limited provides a Māori-language interface option. An initial pilot study indicated users will engage with this interface, but when pushed for time will switch the interface to the English-language option. This paper reports on a study undertaken to test the usability of the smartphone Māorilanguage interface. Participants reported difficulties and some frustration as they struggled with new words and unfamiliar uses of words. They also expressed disappointment at poor translations and arbitrary truncations. The feedback highlights perceived shortcomings encountered when technologies that are normally developed and used in a major language are translated for use in minority Indigenous languages. Māori-language strategies that consider using translated application interfaces should be cognisant of such issues.
\end{abstract}

\section{Keywords}

Māori, translated technology, language shift, technology-driven social change, new media

* PhD Candidate, University of Waikato, Hamilton, New Zealand. Email: pjm20@students.waikato.ac.nz

† Senior Lecturer, University of Waikato, Hamilton, New Zealand.

‡ Research Intern, University of Waikato, Hamilton, New Zealand.

DOI: 10.20507/MAlJournal.2016.5.1.2 


\section{Introduction}

The advent and escalation of technologies that allow constant connectedness have forever changed the method, look and frequency of daily communication and social interaction. The progression of social change over the past 50 years or so has been both unprecedented and substantial (Foundation for Endangered Languages, 2012). New technologies allow the general public to share and participate in a variety of settings and media that were unavailable to them not so long ago. The quickness of the general population to adopt these new media has been described as "astonishing and breath-taking in its momentum" (Cross, 2011, p. 25). From the relatively simple act of viewing the news on a television set and then picking up a telephone and talking to someone about it to experiencing space travel vicariously in real time and participating in a global online discussion during and following that experience is not only a significant leap in terms of the technologies involved but also an enormous transformation in terms of social behaviours, interactions, interrelation and expectations (Cross, 2011; O’Connor, 2012). This transformation is relatively unappreciated and the ability for us to remain digitally connected with each other and the world in general is something that is more expected than admired.

Internet-based technology is constantly evolving. Networking and information dissemination is becoming a matter of course as new tools enable the production, sharing and discussion of news, events, data, information and knowledge (O'Connor, 2012, p. 14). In some instances, modern technology has removed the immediate need to interact and to meet face to face (O'Carroll, 2013a, p. 8). People are now able to easily engage in conversations with friends, family and colleagues by text and audiovisual technology, regardless of the distances that might separate them (Waitoa, Sheyvens, \& Warren, 2015, p. 48). For many, the urgency to return to their homeland, or to hurry home to family and friends, appears somewhat quelled by that effortless online connection (Greenland, 2013). This continuous connectivity may well underpin claims that the deluge of digital technology has caused the biggest shift of global culture since the industrial revolution (Cross, 2011, p. 3). People are now able to employ a myriad of methods to ensure their messages and thoughts are more readily available and much more accessible by others than ever beforeeven more so when using a major language (Cross, 2011, p. 4; O'Connor, 2012, p. 14). However, the advent of global connectedness is not without its pitfalls (Waitoa et al., 2015). Apart from the need to employ a major language in order to remain amplified and widely received, the potential for misappropriation of knowledge is concerning for many Indigenous communities (Dyson \& Underwood, 2006; O'Carroll, 2013a, p. 8; Waitoa et al., 2015, p. 49). This includes using various digital media to share within the public domain what have normally been private conversations and traditions reserved for more cloistered surroundings (O'Carroll, 2013a, p. 9). Perhaps concepts similar to E-whanaungatanga conceived by Waitoa et al. (2015) can provide methods of protecting Indigenous values and traditions not meant for general public consumption. E-whanaungatanga establishes online spaces for the appropriate, respectful and safe engagement by Indigenous peoples (Māori-centric in this case) in ways that focus on ensuring the protection of traditional knowledge sharing that is normally reserved for more intimate, face-toface environments (Waitoa et al., 2015, p. 54).

Social media sites enable a spontaneity and ease of self-expression that is unrivalled in terms of the satisfaction, the instant gratification and the thrill of being able to stay continuously connected with people in a manner that is as good as or sometimes better than being face to face (Cross, 2011, p. 4). Perhaps the biggest attraction is that people are now able to say and share what they want, when they want-to an audience that is perpetually listening. However, 
Cross (2011) observes that one of the most significant side effects of social media is "the blurring of lines between public and private” and how everyone's "hidden exhibitionist and secret desires" have been brought out and able to be made available for public consumption (p. 5). In terms of Indigenous peoples and their cultures, this may well impact on traditional values, conversations and knowledge that were hitherto private and most often the result of face-to-face personal transfers (O'Carroll, 2013a, p. 9). As technology-driven social change spills from the online environment "into the streets" and ethics and etiquette struggle to keep pace, one might pause to wonder how new technology and the pervasion of social media impact on minority languages-especially those already suffering some form of endangerment (Foundation for Endangered Languages, 2013; Waitoa et al., 2015, p. 52).

The saturation of mass media and social media has demanded the use of major languages to maximise the effect of transmission to a wider, if not global, audience. One might also argue that some level of literacy in a major language is necessary to enable the use of such media in the first instance (Jancewicz \& MacKenzie, 2002). In any case, the use of a major language in the digital arena reinforces the foundations for language shift, as Indigenous people opt, for a variety of reasons, to use a language that is perceived to be necessary or more useful. The shift is generally intentional-language speakers will discard their own tongue in favour of one more widely spoken-and is the principal cause of a language being used less and becoming endangered (Austin \& Sallabank, 2011; Fishman, 1991; Grenoble \& Whaley, 2006). Although it is rare for a language to be lost through a sudden loss of its speakers, a few such cases have occurred as a result of a natural disaster, disease or vanquishing and genocide, as in the case of war (Austin \& Sallabank, 2011, p. 27). The extended and gradual decline of a language has been much more common. When speakers cease to speak their own native tongue and move to languages of wider communication (for example, major languages such as English, Mandarin or Spanish), this generally recognises that the "new" language is more useful and more beneficial (Austin \& Sallabank, 2011; Dorian, 1998; Janson, 2002).

Language decline is hastened by speakers who for various reasons decide that another tongue, in their actual circumstances, is a preferable communication tool for themselves and for their children (Janson, 2002, p. 98). It is not uncommon for speakers of minority languages to regard a major national or international language as a "more useful" language option for their children than a "useless" endangered language (Austin \& Sallabank, 2011, p. 11). The spread of dominant languages coupled with the hesitancy of parents to pass their own mother tongue on to their children results in the children growing up learning and speaking the dominant language. Those children and their children may never learn or use their traditional tongue, or they may lose that ability as the language declines in use (National Geographic, 2014 , p. 1). Given that a language is considered to be safe and have the best chance of survival when the children speak the language in a variety of common social settings and situations, it is critical for endangered languages that interventions are enacted to ensure that the language transfer from generation to generation continues through everyday interactions (Chrisp, 2005; Fishman, 1991; Moseley, 2010).

Cases where minority languages, especially those of smaller cultures, have been driven into the background by more powerful groups, whose own languages have thrived, are dotted throughout human history. The dominance of these larger, or major, languages arises because the speakers of these languages also tend to wield economic, political, social and cultural power. This generally leads to the marginalisation of the minority languages, pressuring the speakers of those languages to shift to the dominant tongue (Austin \& Sallabank, 2011, p. 1). According to Kalzner (1995): 
As the number of speakers diminishes in each case, a fateful decision must inevitably be made: the members of the rising generation must abandon their mother tongue and adopt instead a more widely spoken neighboring language that will be of greater use to them. By such a decision the lesser language is literally condemned to death, its ultimate passing awaiting only the death of the last speaker. (p. ix)

As the pressure from major languages steadily increases and smaller language speakers progressively cease to speak their mother tongue to each other or to their children, language loss is hastened. This process is accelerating and indicators predict that there will be drastically fewer languages in just a few generations, despite the expected growth in the world's population (Janson, 2002, p. 236; National Geographic, 2014, p. 1).

With the advent of mass communication, the number of endangered languages under threat of extinction has further escalated-especially as minority languages are pushed further into the media background (Gasser, 2006). This is partly due to the resulting propagation of major languages in areas where until now only minor languages were spoken (Kalzner, 1995, pp. ix-x) and partly because "the Digital Revolution is not reaching all populations in a uniform fashion" (Gasser, 2006, p. 2). It is evident that the dominance of major languages in burgeoning contemporary technologies is adding pressure to minority language speakers to communicate in the dominant tongue (Gasser, 2006; Kalzner, 1995). Linguists predict that about half of the 6,000 to 7,000 languages currently spoken are likely to be lost within the next few generations as a result of the increasing pressure to use a major language (Austin \& Sallabank, 2011; Harrison, 2007; Janson, 2012). Most at risk of being lost are the many Indigenous languages whose speakers often use a major language, such as English, at the very least to enable the review of their broadcasts by a wider audience. As the shift to use a majority language continues, the smaller languages are being pushed nearer to the brink of extinction (Borrero, 2013; UNESCO Ad hoc Expert Group on Endangered Languages, 2003). In terms of the new media forms, what and where are the windows of opportunity for the smaller languages?

Te reo Māori, the Indigenous language of Aotearoa New Zealand (hereafter referred to as New Zealand), is undergoing a renaissance of sorts as language activists seek to restore language vibrancy and vigour (O'Carroll, 2013b, p. 232). Language regeneration efforts, especially over the past half century, have produced a variety of initiatives seeking to halt the declining health of te reo Māori and increase the number of fluent speakers. Early language initiatives focused on education and community language development. Recently, the use of contemporary technologies has been making significant inroads into the areas of language acquisition, wider communication and networking. The development of small online language communities encouraging the use of te reo Màori and the advent of translated application interfaces are slowly embedding a Māori-language profile in various forms of new media. Recent technologies have included translated interfaces for a selection of computer applications, mobile technology, physical self-service machines and social media (Keegan, Mato, \& Ruru, 2015; Mato \& Keegan, 2013a, 2013b). The effect of these tailored resources would be enhanced by strategies that promote awareness and encourage their extended use in the target language.

A smartphone launched by Two Degrees Mobile Limited in 2011 provides a Māorilanguage interface option. A pilot study indicated users will use the Māori-language interface but will switch to English when they consider the navigation is unnecessarily prolonged or difficult. These users reported high levels of language switching because, although they wanted to use te reo Mãori, they found it easier to use the English-language interface 
when they needed to complete tasks quickly. This paper reports on testing that was undertaken following the pilot study to gauge the usability of the Māori-language interface.

\section{Two Degrees Mobile Limited -background}

Two Degrees Mobile Limited, better known in New Zealand as 2degrees, was launched in 2009 and is one of New Zealand's newest mobile telecommunications companies. The company is $60 \%$ owned by Trilogy International Partners-a Seattle-based private telecommunications company providing wireless communication services through three operating companies, in New Zealand, Bolivia and the Dominican Republic. Trilogy acquired $26 \%$ of a mobile wireless operator in New Zealand, then called New Zealand Communications Limited, in June 2008 and renamed the company Two Degrees Mobile Limited (Trilogy International Partners, 2014).
Te Huarahi Tika Trust is a charitable trust incorporated in 2000, in consultation with the New Zealand government, to enable Māori to have a preferential right of purchase over certain radio frequencies (primarily thirdgeneration spectrum [3G]) being auctioned by the government at that time. The trust lobbied the government to develop an appropriate regulatory framework and at the same time sought joint venture partners to work with (Te Huarahi Tika Trust, 2013). This led to the establishment of New Zealand's third mobile network-Two Degrees Mobile Ltd. Te Huarahi Tika Trust established Hautaki Limited to be the corporate trustee for Hautaki Trust, which was established as the entity that would have the exclusive opportunity to purchase management rights over certain radio frequencies and pursue the commercial development of these rights on behalf of Māori (see Figure 1). Te Huarahi Tika Trust has increased its shareholding in 2degrees from $10.3 \%$ to $11 \%$ (Pānui, 2011; Te Huarahi Tika Trust, 2013).

Two Degrees Mobile Limited launched

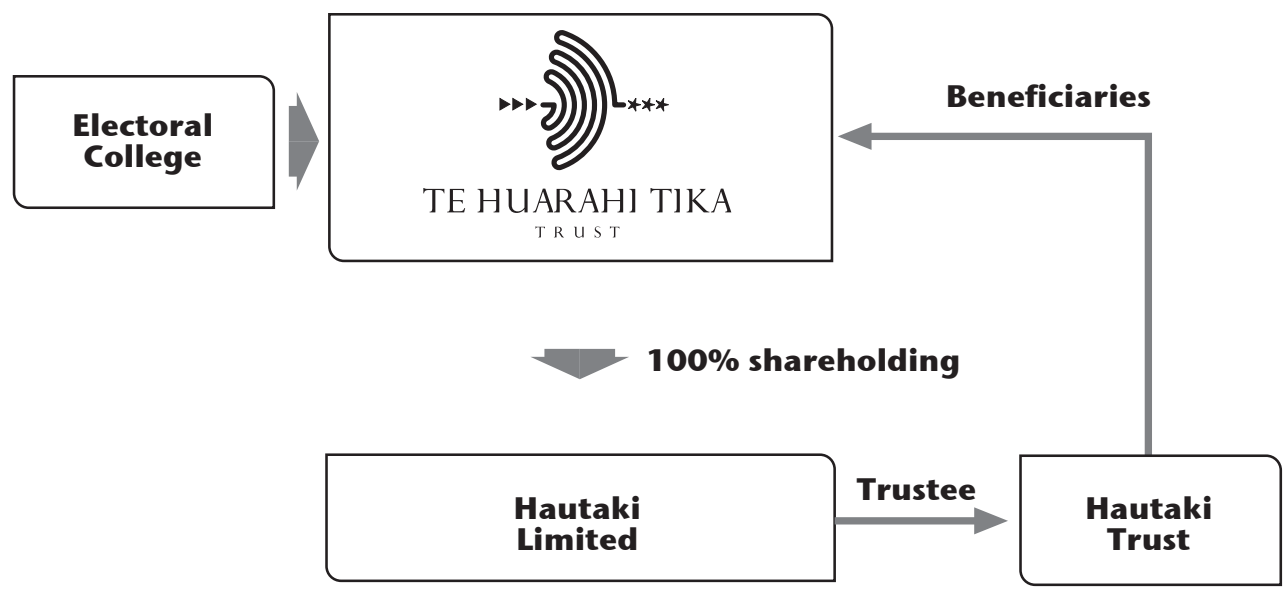

Shareholding

2 Degrees Mobile Ltd

FIGURE 1 Te Huarahi Tika Trust structure (Te Huarahi Tika Trust, 2011, p. 9) 

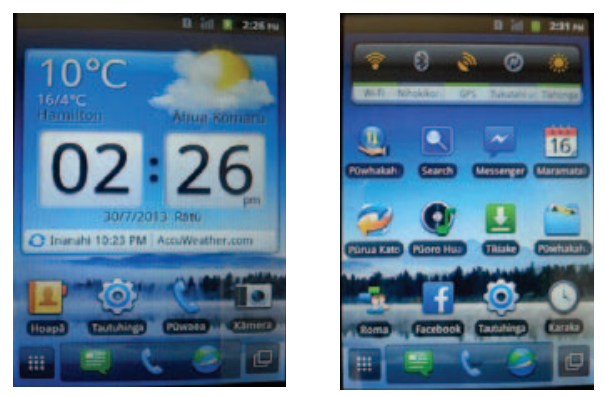

FIGURE 2 Sample screenshots of the Māori-language interface for the IDEOS X3

the first smartphone usable in te reo Māori in November 2011. The Māori-language interface is one language option on the IDEOS X3 smartphone (see Figure 2) and was developed in conjunction with Huawei, a world-leading Chinese-based provider of telecommunication infrastructure.

This particular model was launched in conjunction with Hei Rere Mai ("So You Can Fly"), a program intended to increase participation by Māori in the telecommunications industry (see https://www.2degreesmobile.co.nz/company/ news-and-media-releases/hei-rere-mai-maoricareers-in-telecommunications/). The combined launch fulfils part of the Hautaki Trust vision as co-founders of 2 degrees to make te reo Māori available in today's technology (Te Huarahi Tika Trust, 2013). The trust states that engaging Māori in the telecommunications industry and ensuring that the Māori culture and language are embraced by modern information and communications technology are primary objectives.

\section{Pilot study}

A short pilot study was undertaken in 2014 to determine whether the 2 degrees smartphone Māori-language interface was a practicable option for Māori-language speakers. The smartphone was independently used as a primary phone by four Māori-literate testers for between five and seven days each. Their comments indicated high levels of language switching and some frustration as new words and often unfamiliar use of words were encountered. As a result, none remained fully engaged with the Māori-language interface, preferring to switch to the English-language version, especially when wanting to quickly complete the task at hand. Given the informal nature of this testing, we clearly needed a more formal analysis to determine the usability of the Māorilanguage interface.

\section{Usability study}

A usability study was undertaken using the Huawei smartphone to substantiate the feedback from the pilot study. The size of the usability study was restricted by the short time frame (a 12-week funding period) and limited resources (one phone and one research facilitator). The sample size of 12 participants is reflective of these constraints of time and resource.

Usability studies refer to the evaluation of a product or service by assessment through a usability test. Generally, such tests focus on measuring a product's capacity to meet its intended purpose. Usability experts also expect the product to be quick to use, relatively error free and able to be used or navigated with some level of intuition (Johnson, 2008; Krug, 2014). Simplistically, a person should be able to use the product to accomplish what is expected without the experience being more trouble than it is worth (Krug, 2014, p. 9). Our study aimed to determine whether the phone's Māorilanguage interface could be used to easily and 
TABLE 1 Age and gender of participants

\begin{tabular}{llll}
\hline & $18-25$ & $25-35$ & $35+$ \\
\hline Female & 3 & 2 & 2 \\
Male & 3 & 1 & 1 \\
\hline
\end{tabular}

efficiently complete tasks that might be considered standard on a smartphone. Participants were asked to note the ease of use, the speed and efficiency of task completion, and the existence of any mistakes or flaws in terms of the language used. The participants were also asked to rate their experience and share their perceptions regarding the effectiveness and usefulness of a Māori-language interface on a smartphone. We were interested in how well the interface provided for intuitive use-were users able to find their way around the menus and icons relatively easily and quickly? Additionally, how did the participants think the Māori-language interface might affect language use and ongoing language health?

The study objectives were (a) to determine whether tasks could be completed successfully, (b) to determine whether tasks could be completed quickly and easily, (c) to determine whether navigation could be done intuitively, (d) to verify the quality of the translations, (e) to determine levels of participant satisfaction and perception, and ( $f$ ) to identify barriers to the Māori-language interface being the preferred option.

\section{Participants}

Twelve participants were chosen based primarily on their fluency and understanding of te reo Māori. They all had some competence and confidence with the use of smartphones and similar technologies. The ages, gender and language fluency of the participants are shown in Tables 1 and 2.
TABLE 2 Māori-language fluency levels of participants

\begin{tabular}{ll}
\hline Intermediate & 3 \\
Fluent or first language & 9 \\
\hline
\end{tabular}

\section{Methodology}

The purpose and structure of this usability study were explained to the participants and the questionnaire was discussed. A brief overview of the wider research project was also provided. The wider project investigates the awareness and perception of Māori-language use in selected contemporary technologies, including the issues encountered when engaging with these technologies using te reo Māori. The participants were set three tasks using the smartphone Māori-language interface: (a) send and receive a text message, (b) connect to and search the internet, and (c) connect to Facebook and write a post.

Following the completion of these tasks, participants were asked to use the smartphone to complete their own choice of tasks using both the Māori-language and the English-language interfaces. Finally, the participants were asked to provide feedback by completing a short questionnaire.

\section{Results}

The following is an overview of the participant feedback gathered from the completed questionnaires.

1. How understandable were the screen commands in te reo Māori?

Seventy-five percent of the participants reported some difficulty interpreting the screen commands-especially during the initial part of the testing. Four testers found the icons and graphics to be hugely beneficial for understanding what the different commands were for, and 
two found the commands understandable and the phone easier to comprehend after some prolonged use.

\section{What were the main difficulties in using these interfaces and why?}

Almost all of the respondents struggled with unfamiliar words and found tasks took a bit longer to complete because of the extra time required to decipher what the words and messages meant and then "connect the word to the image and action for the interface". Some of the longer words were not fully visible on the screen; their resulting abbreviated forms added to the confusion or were not well received. Participants gave the example of the shortening of days of the week to M/T/W. It was not clear whether these particular letters abbreviated the transliterated Māori word or the English word since the first letters are the same in the two languages for these three days. Participants also reported the use of kupu in the wrong context and that some words may have been just a bit too literal. One example of wrong context was "e uta ana", which means to load (a burden), used for to retrieve information or run (load) an application. Another example was nihokikorangi used for bluetooth. Although niho translates to English as "teeth" and kikorangi translates as the colour "blue", it was felt a better word could have been used (although no alternative was suggested).

\section{How did it make you feel to see your lan-} guage used in this manner?

All the participants agreed that the use of te reo Māori in a smartphone was a positive move that promoted the language and kept it visible on contemporary technologies. Two of the participants were more cautious and advocated keeping the integrity of the kupu and ensuring the translations were accurate and easy to understand. In general, the responses indicated the participants were pleased and proud to see this blending of te reo Māori and technology and considered that the use of the reo in this manner, on day-to-day technologies, would strengthen and support the ongoing use and health of the language.

4. Do you think te reo Māori in these and similar interfaces would encourage the use of te reo Māori?

Most of the participants ( 8 of the 12) agreed that translated interfaces used more often by many people on a regular basis would definitely encourage the use of te reo Māori. A quarter of the respondents were not convinced, citing the difficulty with new words and unclear translation as distinct barriers to the extended use of the translated technologies. Feedback also indicated that although users might choose to receive or view their communications using te reo Māori, it was felt that further engagement would most likely occur in English.

Examples of other feedback include:

Āe, pēnā ka kite atu a tātou rangatahi he wāhi mō te reo i te ao hangarau ka rarata pea ki te kōrero ki waho i te akomanga, $\bar{a}$, he reo e ora ana. (Yes, if our youth see that there is a place for the reo in the technology world they may just get used to speaking the reo outside of the classroom, from there our language is living.)

At this moment I feel it would not encourage many as there are a lot [of] Māori words [that] need to be spelled in full to give an understanding. Technology users find [it] easier to use a smaller word.

5. How would you suggest normalising the use of these interfaces in te reo Māori so that others would be more likely to use them?

Some of the participants regarded promotion of the language using online technology and associated applications such as e-books and Māori-language television shows as key to normalisation. The majority of the feedback (7 of the 12) were quite clear that simplifying the words or making them more understandable somehow would definitely help normalise the 
use of translated interfaces. One person suggested the Māori-language interface should be available on all phones and another suggested raising the general awareness that this type of product was available.

6. If the interface were in te reo Māori (but switchable to English) how useful would this be to encouraging the use of te reo Māori?

The participants were evenly split on whether or not the translated interface would encourage the use of te reo Māori. Half thought the ease and quickness associated with interacting with the English-language interface would discourage users from using the Māori-language version. Most of the feedback mentioned language fluency as a compelling factor and most of the consensus hinged on prolonged engagement being underpinned by higher levels of language capability. Two people thought the interface in te reo Māori would benefit those aiming to learn the language and one believed the interface should only be available in te reo-supported by the use of icons.

\section{Which language interface were you more comfortable using?}

Māori English

\section{Which language} interface was quicker or easier to use?

\section{Which language interface would you prefer to use?}

$\begin{array}{ll}2 & 10 \\ 0 & 12 \\ 9 & 3\end{array}$

Participants found that the use of the Māorilanguage interface took a little too long to complete tasks. The existing familiarity with English-language interfaces and having to take time to understand the use of new and unfamiliar words (in Māori) meant that all were far more comfortable using the English-language version. However, in spite of the difficulties of using the phone in te reo Māori, most of the users (9 of 12) reported they would still prefer to engage using the Māori-language interface.

\section{The final question asked for further} comments.

Most of the feedback indicated pleasure and pride in seeing the Māori language used in this manner and in this type of environment. A quarter of the responses suggested that this and other similar interfaces would promote the learning and use of the language. Another quarter reported levels of discomfort with the way some words were used out of context, the existence of some English words on the Māori-language interface, the poor use of transliterations and the abbreviating of some words. One example of poor abbreviation features days of the week-Rāhina shortened to "Hī" and Rātū shortened to "Tū". An example of poor context was atahanga-whakaahua was thought to be a better, more familiar translation.

\section{Discussion}

Although the size of this study was quite small, much of the feedback was similar to that of other studies with a focus on Māori-language interfaces (Mato \& Keegan, 2011, 2013b; Mato, Keegan, Cunliffe, \& Dalley, 2012). Prior to the usability study, the participants were unaware of the Māori-language option for the smartphone interface and expressed some surprise to see te reo Māori in this type of environment. They were excited and proud to see te reo Māori used on this technology and derived some pleasure at being able to interact with the technology in their own language.

Difficulties were reported with unfamiliar words and the unfamiliar use of words. Other studies conducted on Māori-language interfaces for applications such as Microsoft Office, Windows, the Google Web Search interface and library self-issue machines reported similar issues with new words, words used in different contexts, and the creation of words that were 
literal translations but did not quite convey an accurate meaning (as in the bluetooth example in Question 2) (Mato et al., 2012; Mato \& Keegan, 2013b; Mato, 2015). In spite of those difficulties, most of the respondents would prefer to engage with the Māori-language interface even though they reported having to take extra time to determine what some of the on-screen menus, icons and instructions meant. The overriding consensus of the users, however, is that they would revert to the English-language versions when tasks needed to be finished quickly.

Whether or not the use of translated interfaces would assist learners of the language and encourage ongoing language use generated some thoughtful feedback. The responses were divided. Some were wary that the difficulties in understanding words and instructions would hinder fluent speakers of te reo Māori and that learners of the language would struggle. Others believed the extended use of the language within the technology would enable users to come to grips with the translated interfaces in a relatively short period. Some felt that the prolonged use of Māori in technology would encourage others to communicate in a similar fashion to the point where the use of te reo Màori in smartphone technology would eventually be perceived as "normal".

Nearly half of the participants expressed some discomfort with the translations. They cited new words, unfamiliar use of words, poor translation and arbitrary truncation as points of concern. Some thought the use of literal translations did not quite capture the essence or give a clear description of the action. A small percentage also expressed a view that the translation should be complete and the Māori-language interface should not contain English words.

Returning to the objectives of the study:

1. It is evident that the assigned tasks were able to be completed by all participants.

2. Although the tasks were completed, the respondents reported difficulties using the Māori-language interface and needing extra time to decipher screen instructions and the meanings of some icons.

3. The ease of navigation was impacted by the discomfort experienced by the translations. Although some of the icons were recognisable (from English-language interfaces), participants reported having to take time to ensure they were interpreting the screen directions accurately.

4. All of the participants commented on the quality of translation. Some examples given were words used in ways that were contextually inaccurate, such as "e uta ana", which means to load a burden but was used for to run (or load) information or an application, and the use of nihokikorangi (niho meaning tooth or teeth and kikorangi meaning blue) for bluetooth.

5. In general, the participants were pleased to encounter the use of te reo Mãori on this type of technology but were less than satisfied with the experience, citing the extra time needed to appreciate what was displayed on the screen, the lack of intuitive navigation and being unable to quickly complete standard tasks as a result.

6. The main barriers to the Māori-language interface being the preferred option for the participants were difficulties with translations that were unfamiliar, contextually inaccurate or arbitrarily truncated. All the participants agreed that an existing familiarity with English-language versions of smartphone interfaces affected how easy the Māori-language version was to use, and some suggested that this might be somewhat alleviated over time by extended use in te reo Māori.

Given that all the participants were already experienced in interacting with this type of technology, it is likely that the initial difficulties described arise from a previous competence in another language-in this case English. This is supported by observations in the Indigenous Languages and Technology (ILAT) 
discussion forum (see http://www.u.arizona. edu/ cashcash/ILAT.html), that "exposure to contemporary technology in the dominant language could impede the use of contemporary technology in the minority and/or endangered language" (Bischoff, 2011, p. 6). Furthermore, Jancewicz and MacKenzie (2002) refer to a prerequisite of some literacy in a major language when initially engaging with contemporary technologies (p. 90), inferring that it might already be necessary to have a prior competence in a major language before attempting to engage with the technology using a minority language.

Overall, the reaction to seeing that the technology could be used in te reo Māori was positive. Following the usability testing, however, the feedback indicated participants were less than satisfied with the experience. Although there was a majority preference for using the Māori-language interface, testers unanimously agreed they experienced frustration as they tried to decipher accurate meaning from the Māori words that were chosen to identify the icons and menu items.

Given that the responses consistently mention the theme of struggling with new words, unfamiliar uses of words and translations out of context, it would be useful to quickly discuss these issues in the context of fluency and technology. Most of the group thought that fluent speakers of te reo would experience some difficulties with the Māori-language interface and that learners of the language would definitely struggle. In terms of the usability of the translated interface, it would appear that to encounter te reo Māori in a new domain would raise enough question marks to distract from the task at hand and hinder the participants' use of the technology (Krug, 2014, p. 15).

\section{Conclusion}

Despite the small sample size and self-reported outcomes, this short usability study regarding the smartphone translated interface has supported the feedback from the initial pilot group and is consistent with the testing of translated interfaces for other applications and technologies. Users were previously unaware of the existence of a Māori-language interface and, upon engagement, found unfamiliarity with the interface terminology and presentation an impediment to expedient use. A user might consider that there is something wrong with the translation or that te reo Māori does not sit well in a technological environment. Given that the assigned tasks were completed and that those who experienced prolonged use of the smartphone began to gain some proficiency in a very short time, it would seem that the difficulties reported generally arose from previous competence in using this technology in another language-in this case English. It is normal to revert to processes and methods that have already produced desired results in an expedient and efficient manner, and the participants in this study were adamant that they would switch to the English-language interface if they were in a hurry or needed to quickly complete the task at hand. Language switching within technology appears to be no different from the language switching within minority language communities. In terms of extended engagement with translated interfaces, it might be more beneficial to highlight and understand the reported difficulties-aiming for a commitment to familiarity and ease of use through prolonged engagement rather than direct comparisons where the minority language is already in a deficit position.

\section{Future work}

To elaborate further on the findings from this usability study, an investigation involving a larger participant group would prove useful. This might be difficult to accomplish in the short term because of a current lack of suitable translated interfaces. The smartphone used in the usability study on which this paper is based was released in 2011 and is now out of date. 
To our knowledge there are no other phones available currently that have an interface that is usable in te reo Māori. It might also be useful to consider a larger study in two parts-one part to gauge new experiences and one part (or perhaps a later study) to test usability. For future studies, would it be useful to predetermine some of the issues and constraints-that is, so that the usability tests reflect usability rather than new experiences?

\section{Acknowledgements}

We acknowledge and thank Ngā Pae o te Māramatanga at the University of Auckland and the Faculty of Mathematical and Computing Sciences at the University of Waikato for supporting this study and applaud Te Huarahi Tika Trust for enacting part of their vision with the supply of a multilingual smartphone that is usable in te reo Māori.

This study received ethical approval from the Ethics Committee, Faculty of Computing and Mathematical Sciences, University of Waikato, Hamilton.

\section{Glossary}

$\begin{array}{ll}\text { Aotearoa } & \text { New Zealand } \\ \text { atahanga } & \text { image } \\ \text { e uta ana } & \text { to load a burden } \\ \text { kikorangi } & \text { blue } \\ \text { kupu } & \text { word/words } \\ \text { niho } & \text { teeth/tooth } \\ \text { Rāhina } & \text { Monday } \\ \text { Rātū } & \text { Tuesday } \\ \text { te reo Māori } & \text { the Māori language } \\ \text { whakaahua } & \text { image }\end{array}$

\section{References}

Austin, P., \& Sallabank, J. (Eds.). (2011). The Cambridge handbook of endangered languages. Cambridge, England: Cambridge University Press. http://doi.org/bfdj

Bischoff, S. (2011, August 9). Results: Lang Tech Surveys. Indigenous Languages and Technology (ILAT)-Unpublished ListServ Summary for the period 1 January to 1 June 2011. Archived at http://listserv.linguistlist.org/pipermail /ilat/2011-August/007057.html.

Borrero, R. M. (2013). Innovation and technology for indigenous peoples. Retrieved from http:// www.un.org/esa/socdev/egms/docs/2013/ict /innovation-technology-indigenous

Chrisp, S. (2005). Māori intergenerational language transmission. International Journal of the Sociology of Language, 172, 149-181. http://doi.org/bjn4wg

Cross, M. (2011). Bloggeratti, twitterati: How blogs and Twitter are transforming popular culture. Oxford, England: Praegar.

Dorian, N. (1998). Western language ideologies and small-language prospects. In L. A. Grenoble \& L. J. Whaley (Eds.), Endangered languages: Current issues and future prospects (pp. 3-21). Cambridge, England: Cambridge University Press. http://doi.org/bfdk

Dyson, L. E., \& Underwood, J. (2006). Indigenous people on the Web. Journal of Theoretical and Applied Electronic Commerce Research, 1(1), 65-76. Retrieved from http://www.jtaer.com /apr2006/dyson_underwood_p6.pdf

Fishman, J. (1991). Reversing language shift: Theoretical and empirical foundations of assistance to threatened languages. Philadelphia, PA: Multilingual Matters.

Foundation for Endangered Languages. (2012). The XVI FEL Conference-Language Endangerment in the 21st Century: Globalisation, Technology \& New Media. Retrieved from http://poliglotti4.eu/php /media-centre/index.php?doc_id=2047\&lg=en

Foundation for Endangered Languages. (2013). The FEL manifesto. Retrieved from http://ogmios .org/manifesto/index.htm

Gasser, M. (2006, October). Machine translation and the future of indigenous languages. Paper presented at I Congreso Internacional de las Lenguas y Literaturas Indoamericanas, Temuco, Chile. Retrieved from http://www.cs.indiana.edu/pub /gasser/cilli.pdf 
Greenland, A. (2013, September 22). For internet pricing that's fair Govt needs to butt out [News item]. Retrieved from http://thtt.co.nz/for-internet -pricing-thats-fair-govt-needs-to-butt-out/

Grenoble, L., \& Whaley, L. (2006). Saving languages: An introduction to language revitalization. Cambridge, England: Cambridge University Press.

Harrison, K. D. (2007). When languages die: The extinction of the world's languages and the erosion of human knowledge. New York, NY: Oxford University Press. http://doi.org/bnb3rf

Jancewicz, B., \& MacKenzie, M. (2002). Applied computer technology in Cree and Naskapi language programs. Language Learning and Technology, (6)2, 83-91. Retrieved from http://llt.msu.edu /vol6num2/pdf/jancewicz.pdf

Janson, T. (2002). Speak: A short history of languages. Oxford, England: Oxford University Press.

Janson, T. (2012). The history of languages: An introduction. Oxford, England: Oxford University Press.

Johnson, J. (2008). Gui bloopers 2.0 common user interface design don'ts and dos. Burlington, MA: Elsevier.

Kalzner, K. (1995). The languages of the world. London, England: Routledge.

Keegan, T. T., Mato, P., \& Ruru, S. (2015). Using Twitter in an Indigenous language: An analysis of te reo Māori tweets. AlterNative, 11(1), 59-75.

Krug, S. (2014). Don't make me think, revisited: A common sense approach to web and mobile usability. San Francisco, CA: New Riders.

Mato, P. (2015). Translated application interfacesissues of engagement. In A. Hinze, D. M. Nichols, \& M. Masoodian (Eds.), Proceedings 15th New Zealand Conference on Human-Computer Interaction (pp. 1-4). Hamilton, New Zealand: ACM. http://doi.org/bfdm

Mato, P., \& Keegan, T. T. (2011, February). Are computer applications being used in Te reo Māori? Some initial findings. Paper presented at the 2nd International Conference on Language Conservation and Documentation: Strategies for Moving Forward, University of Hawai'i at Mānoa, Hawai'i. Retrieved from http://hdl .handle.net/10125/5184

Mato, P., \& Keegan, T. T. (2013a, June). The use of blogging and micro-blogging to develop online Māori-language communities: Proposed research. An extended abstract presented at the Canada International Conference for Education, University of Toronto, Toronto, Canada.
Mato, P., \& Keegan, T. T. (2013b, June). Using technology in an indigenous language: Preliminary studies of ATMs and library kiosks usage in te reo Māori. Paper presented at the Native American \& Indigenous Studies Association (NAISA) Conference, University of Saskatchewan, Saskatoon, Canada.

Mato, P., Keegan, T. T., Cunliffe, D., \& Dalley, T. (2012). Perception and use of software with a Māori-language interface in Māori-medium schools of New Zealand. In T. Ka'ai, M. Ó Laoire, N. Ostler, R. Ka'ai-Mahuta, D. Mahuta, \& T. Smith (Eds.), Proceedings of the Conference FEL XVI, Language Endangerment in the 21st Century: Globalisation, Technology and New Media (pp. 87-92). Auckland, New Zealand: Te Ipukarea and Printsprint, AUT University.

Moseley, C. (Ed.).(2010). Atlas of the world's languages in danger (3rd ed.). Paris, France: UNESCO Publishing. Retrieved from http://www.unesco .org/culture/en/endangeredlanguages/atlas

National Geographic. (2014). Disappearing languages: Enduring voices-Documenting the planet's endangered languages. Retrieved from http://travel.nationalgeographic.com/travel /enduring-voices

O’Carroll, A. D. (2013a). Māori identity construction in SNS. International Journal of Critical Indigenous Studies, 6(2), 2-16. Retrieved from http://www.isrn.qut.edu.au/publications /internationaljournal/documents/volume6 _number2_13-OCarroll.pdf

O'Carroll, A. D. (2013b). Virtual whanaungatanga: Māori utilizing social networking sites to attain and maintain relationships. AlterNative, 9(3), 230-245.

O'Connor, R. (2012). Friends, followers and the future: How social media are changing politics, threatening big brands and killing traditional media. San Francisco, CA: City Light Books.

Pānui. (2011, June 16). Hautaki Trust purchases more shares in 2 degrees [Current affairs post]. Retrieved from http://www.panui.net/2011/06/16 /hautaki-trust-purchases-more-shares-in-2 -degrees/

Te Huarahi Tika Trust. (2011). Annual report. Retrieved from http://www.thtt.co.nz/publica tions/Annual- Report- 2011.pdf

Te Huarahi Tika Trust. (2013). Home. Retrieved from http://thtt.co.nz

Trilogy International Partners. (2014). Te reo Māori smartphone. Retrieved from http://www.trilogy -international.com 
UNESCO Ad hoc Expert Group on Endangered Languages. (2003). Language vitality and endangerment. Retrieved from http://www.unesco.org/ culture/ich/doc/src/00120-EN.pdf
Waitoa, J., Scheyvens, R., \& Warren, T. R. (2015). E-whanaungatanga: The role of social media in Māori political empowerment. AlterNative, (11)1, 45-58. 


\section{Appendix-Usability study questionnaire}

Tasks/Questionnaire

Ethics Committee, Faculty of Computing and Mathematical Sciences

How usable is te reo Māori on a smartphone?

ID No.

Tasks:

- Send and receive a text message

- Connect to and search the internet

- Connect to Facebook and write a post

Questionnaire

1. How understandable were the screen commands in te reo Māori?

2. What were the main difficulties in using these interfaces, i.e., were there new words, how correct was the use of te reo Māori, were the instructions and options difficult to follow, why?

3. How did it make you feel to see your language used in this manner?

4. Do you think using te reo Māori in these and similar interfaces would encourage the use of te reo Māori (written and spoken)? 
5. How would you suggest normalising the use of these interfaces in te reo Mãori so that others would be more likely to use them?

6. If the interfaces were in te reo Māori (but switchable to English) how useful would this be to encouraging the use of te reo Māori?

a. How do you think people who are not fluent in te reo Māori would react?

(Following the use of the English-language interfaces)

7. Which language interface were you more comfortable using? Māori

Māori English

9. Which language interface would you prefer to use?

Māori English

a. Please explain why ...

10. Do you have any final comments or thoughts? 